\title{
Competências sociais de usuários de um Centro de Atenção Psicossocial
}

\author{
Isabella de Freitas Silva ${ }^{1}$ \\ Tatiane Mitleton Borges Ramos ${ }^{2}$ \\ Francine Baltazar Assad ${ }^{3}$ \\ Luiz Jorge Pedrão 4 \\ Adriana Inocenti Miasso 4
}

\begin{abstract}
Este estudo teve como objetivo verificar a influência dos jogos teatrais nas competências sociais de pessoas com diagnósticos de transtornos mentais de um Centro de Atenção Psicossocial (CAPS). Pesquisa qualitativa, utilizando o Fichário de Jogos Teatrais de Viola Spolin; um guia de técnicas teatrais para a realização dos jogos e um roteiro de entrevista aplicado aos participantes do estudo, antes e após os oito encontros, baseado na Escala de Avaliação de Competência Social em Pacientes Psiquiátricos. Os resultados mostraram que os jogos tiveram influência positiva nas competências sociais e sinalizaram terem um grande potencial para serem transformados em oficinas terapêuticas nos CAPS.
\end{abstract}

Descritores: Psiquiatria; Centros de Reabilitação; Terapia pela Arte.

\footnotetext{
${ }^{1}$ Enfermeira.

${ }^{2} \mathrm{PhD}$, Psicóloga, Prefeitura Municipal de Ibaté, Ibaté, SP, Brasil.

${ }^{3} \mathrm{PhD}$, Terapeuta Ocupacional, Centro de Atenção Psicossocial II, Prefeitura Municipal de São Carlos, São Carlos, SP, Brasil. ${ }^{4} \mathrm{PhD}$, Professor Doutor, Escola de Enfermagem de Ribeirão Preto, Universidade de São Paulo, Centro Colaborador da OPAS/OMS para o Desenvolvimento da Pesquisa em Enfermagem, Ribeirão Preto, SP, Brasil.
} 


\section{Social skills of users of a Psychosocial Care Center}

This study aimed to verify the influence of theater games in social skills of people with diagnoses of mental disorders of a Psychosocial Care Center (CAPS). Qualitative research, being conducted eight meetings using theater games.The binder of Viola Spolin Theater Games, a guide of theatrical techniques for the hosting of the games and screenplay by interview applied to participants of the study, before and after eight meetings, which was based on the Social Competence Assessment Scale in Patients psychiatrists. The results showed that the games had a positive influence on the skills and social skills and have signaled a great potential to be transformed into therapeutic workshops in CAPS.

Descriptors: Psychiatry; Rehabilitation Centers; Art Therapy.

\section{Habilidades sociales de los usuarios de un Centro de Atención Psicosocial}

Este estudio tuvo como objectivo verificar la influencia de juegos teatrales en habilidades sociales de las personas con diagnóstico de transtornos mentales en un Centro de Atención Psicosocial (CAPS). La investigación cualitativa, siendo cumplidos ocho reuniones con juegos teatrales un guía de trabajo de técnicas teatrales para la celebración de los juegos y um guia de entrevista aplicado a los participantes del estúdio, antes y despúes de ocho reuniones, que se basó em la Escala de Evaluación de la Competencia Social en los Pacientes Psiquiátricos. Los resultados mostraron que los juegos tuvieron una influencia positiva en las habilidades y destrezas sociales y han manifestado un gran potencial para ser transformado em talleres terapéuticos en los CAPS.

Descriptores: Psiquiatría; Centros de Rehabilitación; Terapia con Arte.

Introdução

A reforma psiquiátrica tem por objetivo substituir o modelo de cuidado à saúde mental; antes realizado nos hospitais psiquiátricos, numa abordagem biológica e centrada no transtorno mental; para um modelo de cuidado centrado no sujeito, que tem como referência um serviço substitutivo do hospital psiquiátrico, de base territorial, que são os Centros de Atenção Psicossocial $(\text { CAPS) })^{(1)}$.

A reabilitação psicossocial é um dos objetivos principais da reforma psiquiátrica brasileira, que pretende o desenvolvimento das habilidades sociais na comunidade, além da promoção da cidadania em três cenários: habitat, rede social e trabalho(2).
Esse artigo traz o CAPS como espaço para o desenvolvimento das competências sociais de seus usuários.

Competência Social é um critério que tem a função de avaliar se o comportamento de um indivíduo é coerente com a situação social, e se é efetivo para alcançar os resultados preestabelecidos ${ }^{(3)}$. Ela investiga se as habilidades sociais foram aprendidas pelo sujeito para ele se adequar ao seu contexto e ser aceito socialmente. A competência social é composta pelas "medidas moleculares" da competência social: agrupamento verbal, agrupamento não verbal, agrupamento paralinguístico, agrupamento de expressividade emocional e agrupamento de solução de problemas. 
O agrupamento verbal é a habilidade de se expressar por meio das palavras. O agrupamento não-verbal corresponde ao contato visual, movimentos corporais, movimentação de cabeça e gestos que auxiliam a fala. O agrupamento paralinguístico é caracterizado pelo tom de voz, articulação de palavras, ritmo da fala, perturbações e repetições silábicas no discurso. 0 agrupamento de expressividade emocional refere-se à habilidade de transmitir a emoção durante o discurso, e se ela é correspondente à situação, em nível de tipo de emoção e intensidade. O agrupamento de solução de problemas é a habilidade de o sujeito conseguir propor espontaneamente uma solução realista para a situação em que está inserido(4).

$\mathrm{Na}$ literatura, as técnicas que abordam a competência social em pessoas com diagnóstico de transtornos mentais incluem entrevistas ${ }^{(5)}$; inventários ${ }^{(6)}$; técnicas derivadas da sociometria(7); autos registros ${ }^{(8)}$ observação direta do comportamento em situação natural $^{(9)}$ e desempenho de papéis ${ }^{(4)}$.

Há relatos que o desempenho de papéis pode ser observado, por exemplo, por meio de jogos teatrais, os quais possibilitam o desenvolvimento das competências sociais, pois abordam diretamente competências sociais como a expressão verbal, não verbal, paralinguística, de expressividade emocional e de solução de problemas.

Os jogos teatrais fazem parte das terapias expressivas, que no contexto da reabilitação psicossocial, privilegiam a expressão como meio de desenvolver o cognitivo, o corporal, o expressivo e o comportamental. Eles possuem em si finalidades terapêuticas de reabilitação e de ressocialização, de ajuste emocional, de introspecção, de redução do estigma e de prevenção do desconforto(10). Nise da Silveira ao utilizar terapias expressivas em grupos de pacientes psiquiátricos já enfatizava o valor terapêutico das atividades expressivas ${ }^{(11)}$.

O presente estudo tem como objetivo verificar a influência dos jogos teatrais nas competências sociais de usuários de um Centro de Atenção Psicossocial.

\section{Método}

Trata-se de pesquisa descritiva, com abordagem qualitativa, que segue os procedimentos da análise de conteúdo ${ }^{(12)}$.

O estudo utilizou o Fichário de Jogos Teatrais de Viola Spolin como referência para aplicação dos jogos teatrais, o qual é um guia para ensinar técnicas teatrais para jovens, em ambiente escolar, no intuito de oferecer técnicas de ensino/aprendizagem, por meio dos jogos e soluções de problemas ${ }^{(13)}$.

Também se utilizou um roteiro de entrevistas, construído pelos pesquisadores, o qual foi elaborado a partir do referencial teórico das cinco subescalas da Escala de Avaliação de Competência Social em Pacientes Psiquiátricos (EACS) ${ }^{(14)}$. A EACS é uma escala tipo Likert de 6 pontos ou cotas globais, distribuídos conforme: Incompetência (1-2 pontos), Competência média (3-4 pontos) e Competência superior à média (5-6 pontos) atribuídas através da observação sistemática do comportamento em desempenho de papéis ${ }^{(14)}$. AEACS aponta que, a competência social pode ser avaliada também pelos observadores com cinco subescalas: habilidade verbal, não verbal, paralinguistica, de expressividade emocional e de solução de problemas. Os pesquisadores desse estudo elaboraram as questões a fim de compreender a influência dos jogos nas competências sociais dos participantes após os oito encontros; com as seguintes questões: 1- Quando você precisa se comunicar com alguém você consegue expressar suas necessidades? Dê um exemplo. 2 Quando conversa com outra pessoa você consegue falar dos seus sentimentos? Dê um exemplo. 3- Você acha que você fala com um tom de voz mais alto ou mais baixo quando você conversa com as pessoas? 4 - Quando você conversa com outra pessoa, você fala rápido ou fala mais lento? 5- Você acha que você consegue falar claramente as palavras, vogais e consoantes, sem enrolar a língua? 6 - Quando você está conversando com alguém você acha que consegue mostrar, através do seu rosto, a sua emoção? 7 - Quando conversa com outra pessoa você faz uso de gestos e olha pra pessoa quando está se comunicando com ela? 8 - No seu dia a dia, você consegue encontrar soluções para os problemas que surgem como, por exemplo, encontrar soluções quando tem algum problema quando você está arrumando sua casa? Dê um exemplo?

O presente estudo faz parte do projeto denominado: "A recreação no processo de reabilitação de portadores de transtornos mentais em um Centro de Atenção Psicossocial”, que tem com critério a reabilitação psicossocial dos portadores de transtornos mentais através de técnicas expressivas grupais como música, dança, teatro e pintura. O projeto foi apreciado e aprovado por Comitê de Ética, sob o Protocolo $\mathrm{n}^{\circ}$ 0807/2007. Os familiares/ responsáveis assinaram o Termo de Consentimento Livre e Esclarecido e posteriormente os participantes o também assinaram.

A caracterização dos sujeitos é demonstrada na Tabela 1. 
Tabela 1. Caracterização dos sujeitos participantes do estudo. Ribeirão Preto, SP, Brasil, 2013

\begin{tabular}{ccccc}
\hline Participante $(P)$ & $\begin{array}{c}\text { Idade } \\
\text { (anos completos) }\end{array}$ & Gênero & $\begin{array}{c}\text { Diagnóstico psiquiátrico } \\
(\text { CID10 })^{(15)}\end{array}$ & $\begin{array}{c}\text { Tempo de } \\
\text { acompanhamento no } \\
\text { serviço (anos completos) }\end{array}$ \\
\hline P1 & 51 & Feminino & F33 & 06 \\
P2 & 38 & Feminino & F31e F20 & 04 \\
P3 & 55 & Feminino & F31 e F20 & 17 \\
P4 & 34 & Masculino & F33 & 15 \\
P5 & 48 & Feminino & F20 & 17 \\
P6 & 58 & Feminino & F20 & 04 \\
P7 & 52 & Masculino & F20 & 17 \\
P8 & 34 & Feminino & F71 & 16 \\
P9 & 31 & Masculino & F31 e F20 & 04 \\
P10 & 39 & Masculino & F33 & 03 \\
\hline
\end{tabular}

*CID10: Classificação Internacional de Doenças.

Foram recrutados todos aqueles participantes que faziam parte do projeto de extensão da Escola de Enfermagem da USP de Ribeirão Preto: "A recreação no processo de reabilitação de portadores de transtornos mentais em um Centro de Atenção Psicossocial" e estavam em tratamento no CAPS há pelo menos um ano. Como critérios de inclusão também foram considerados: o projeto terapêutico singular de cada um, considerando demandas/ necessidades relacionadas a competência social, não estar em surto psicótico no momento da realização do estudo, ter disponibilidade de participação nas atividades propostas pela pesquisa, ser capaz de estabelecer uma comunicação com os outros integrantes do grupo, e não possuir limitações físicas para participarem das atividades.

A pesquisa foi realizada em um Centro de Atenção Psicossocial (CAPS) em um município no interior do Estado de São Paulo.

Inicialmente, a entrevista gravada com os participantes foi realizada pelos pesquisadores responsáveis. Sequencialmente foram planejados oito encontros semanais com o grupo de participantes, com duração de uma hora e trinta minutos, nos meses de abril e maio de 2013. Foram dirigidos por uma psicóloga e uma terapeuta ocupacional com formação e experiência em dramatizações e jogos teatrais, e uma aluna de graduação em enfermagem com experiência em oficinas teatrais.

Os encontros foram desenvolvidos em uma sala, também do próprio CAPS, adequada à realização dos jogos teatrais. Após os oito encontros foram realizadas as entrevistas finais, com as mesmas questões iniciais, no intuito de comparação. Para as entrevistas foi utilizado um gravador de voz.
Na Figura 1 está a sequência dos encontros e os respectivos jogos realizados.

Para fins de análise, as entrevistas foram realizadas pelos pesquisadores de maneira individual com cada participante, em uma sala do CAPS, que guardava as devidas condições de sigilo. Foram gravadas em um dispositivo de gravação MP3, transcritas na íntegra e analisadas seguindo os procedimentos da análise de conteúdo temática ${ }^{(12)}$. A análise de conteúdo, enquanto método, torna-se um conjunto de técnicas de análise das comunicações que utiliza procedimentos sistemáticos e objetivos de descrição do conteúdo das mensagens ${ }^{(12)}$, a fim de apontar os núcleos de sentido que possuam algum significado para o objetivo da pesquisa.

\section{Resultados e Discussão}

Após a análise dos dados do material coletado nas entrevistas, os conteúdos provenientes das sínteses das entrevistas iniciais e finais são apresentados a seguir, na forma das categorias que emergiram conforme os temas relacionados a competência social. As iniciais $P$ (1 a 10) referem-se às falas dos participantes.

\section{Agrupamento verbal e paralinguístico}

As características que descrevem a comunicação verbal compreendem as competências verbais e paralinguísticas: falar com clareza, capacidade de articular as palavras, ter o ritmo da fala adequado (nem rápido demais, nem lento demais), o volume da voz ser claramente audível (nem alto demais, nem baixo demais) e a ausência de perturbações na fala (sílabas ou palavras repetidas ou hesitações) ${ }^{(14)}$. 


\begin{tabular}{|c|c|c|}
\hline Encontros & Jogos Teatrais & Objetivos \\
\hline $1^{\circ}$ encontro & $\begin{array}{l}\text { Jogo teatral Blablação(a) - Vender (A86) } \\
\text { Jogo Teatral Blablação - Incidente do passado } \\
\text { (A87) } \\
\text { Jogo Teatral Blablação Português (A88) }\end{array}$ & $\begin{array}{l}\text { Desenvolver a linguagem não-verbal dos } \\
\text { participantes. }\end{array}$ \\
\hline $2^{\circ}$ encontro & $\begin{array}{l}\text { Jogo teatral Dar e Tomar - Aquecimento (B5) } \\
\text { Jogo Teatral Dar e Tomar (B6) }\end{array}$ & $\begin{array}{l}\text { Desenvolver a comunicação não verbal, a } \\
\text { ressonância da fala, a capacidade de ouvir e se } \\
\text { expressar verbalmente, a agilidade verbal, e a } \\
\text { percepção sensorial e temporal. }\end{array}$ \\
\hline $3^{\circ}$ encontro & $\begin{array}{l}\text { Jogo Teatral Aquecimento Sussurro de Cena }{ }^{(\text {b) }} \\
\text { (C15) }\end{array}$ & Propiciar o aquecimento vocal e a agilidade verbal. \\
\hline $4^{\circ}$ encontro & $\begin{array}{l}\text { Jogo Teatral Chicotinho Queimado (A96) } \\
\text { Jogo Teatral Vogais e Consoantes (B46) } \\
\text { Jogo Teatral Diálogo Cantado B47) }\end{array}$ & $\begin{array}{l}\text { Desenvolver a agilidade verbal, o diálogo, a } \\
\text { capacidade de fala e escuta em uma conversa, } \\
\text { a familiaridade e flexibilidade com as palavras, a } \\
\text { fluência verbal e a qualidade tonal e ressonância } \\
\text { da fala. }\end{array}$ \\
\hline $5^{\circ}$ encontro & $\begin{array}{l}\text { Jogo Teatral Fiscalizando um objeto (A41) } \\
\text { Jogo Teatral Modificando a Emoção (C31) }\end{array}$ & $\begin{array}{l}\text { Desenvolver a comunicação não verbal e a } \\
\text { percepção e expressão das emoções. }\end{array}$ \\
\hline $6^{\circ}$ encontro & $\begin{array}{l}\text { Jogo Teatral Construindo uma História }{ }^{(12)}-\mathrm{A} 76 \\
\text { Jogo Teatral Construindo uma História com Emoção } \\
\text { (C30) }\end{array}$ & $\begin{array}{l}\text { Desenvolver a capacidade de escuta dos } \\
\text { participantes, a familiaridade e flexibilidade com as } \\
\text { palavras, a fala e a narração, a leitura e a escrita, a } \\
\text { expressão de emoções. }\end{array}$ \\
\hline $7^{\circ}$ encontro & $\begin{array}{l}\text { Jogo Teatral Irritação Física\# } 1 \text { (C24) } \\
\text { Jogo Teatral Irritação Física \#2 (C25) }\end{array}$ & $\begin{array}{l}\text { Desenvolver a capacidade de comunicação entre } \\
\text { as pessoas, a familiaridade e flexibilidade com as } \\
\text { palavras e o movimento físico e a expressão. }\end{array}$ \\
\hline $8^{\circ}$ encontro & $\begin{array}{l}\text { Jogo Teatral Iluminando (C9) } \\
\text { Jogo Teatral Debate em contraponto \#1 (C10) } \\
\text { Jogo Teatral Debate em contraponto \#3 (C12) }\end{array}$ & $\begin{array}{l}\text { Desenvolver a capacidade de escuta, fala, diálogo, } \\
\text { familiaridade e flexibilidade com as palavras e } \\
\text { tempo presente. }\end{array}$ \\
\hline
\end{tabular}

Figura 1. Jogos teatrais e seus objetivos, conforme o Fichário de Viola Spolin ${ }^{(13)}$.

(a) A técnica de Blablação é importante para liberar o ator da multiplicidade de detalhes técnicos que envolvem o ensaio inicial e para capacitálo a mover-se espontânea e naturalmente no seu papel. Blablação significa, simplesmente, a substituição de palavras articuladas por configurações de sons.

(b) É usado na dramatização, quando os atores simulam um sussurro que pode ser ouvido pela plateia(13).

Quando questionados sobre a comunicação verbal alguns participantes responderam: [...] Consigo! Devagar mais calmo (P4). [...] quando eu tô, eu falo num tom mais baixo, não falo num tom alto [...] Eu falo rápido, não demoro pra falar (P5). Às vezes fico com dificuldade por causa do remédio, falo mole, engulo alguma letra, mas eu gosto de conversar direitinho (P6). Ah, mais ou menos né?! Se está rápido eu dou uma pausa $(\mathrm{P} 7)$.

A maioria dos participantes referiram algumas interferências como, falar num tom de voz extremamente baixo e/ou alto, por vezes falarem rápido ou devagar, "engolir" letras, gerando incompreensão na comunicação. Houve associações do ritmo da fala com os efeitos colaterais das medicações usuais.

Quando questionados se no dia a dia os participantes conseguiam expressar suas necessidades através da fala, suas respostas evidenciaram a tentativa e a dificuldade em serem efetivamente compreendidos, o que impede que a comunicação verbal seja prolongada: Eu tô sentindo dificuldade pra conversar com as minhas filhas que não me entendem né, eu demoro pra falar, eu falo nesse tom com elas, elas já gostam de mudar né [...] eu vou falar e elas não dá muita atenção pro o que eu falo, aí eu ficou nervosa. (P1). Às vezes eu falo né, aí a pessoa fala que não entendeu nada que eu falei, é chato né, mas aí eu falo tudo outra vez porque eu quero conversar (P2). Tem vez que ninguém entende o que tô falando, mas eu tô falando! (P3).

Após as intervenções, quando questionados se conseguiram expressar suas necessidades nos jogos teatrais, os participantes destacaram: [...] consegui, mas foi complicado, [...] É que muitas vezes eu não sabia o que era pra falar [...] foi bom. (P1). [...] na primeira vez eu fui muito ruim, acho que não consegui falar, mas depois eu consegui né. (P3).

Percebe-se nas falas de P1 e P3 que, apesar da dificuldade inicial, os jogos teatrais de Viola Spolin propiciaram condições para que os participantes tivessem liberdade e pudessem exercitar suas capacidades de expressão, em situações muito próximas das situações reais ${ }^{(16)}$, que permitiram a evolução na sua competência verbal. 


\section{Agrupamento não verbal}

Quanto à comunicação não verbal, o uso de gestos foi apontado, por vezes, como um recurso de substituição à comunicação verbal, como por exemplo: Eu sempre tento olhar para as pessoas [...] às vezes quando, por exemplo, a pessoa faz assim pra mim eu faço assim também (movimento de acenar com a mão) (P9). Ah, quando eu chego conversando na rua e eu vejo alguém na linha de ônibus eu faço assim (movimento de acenar com a mão) (P10). Entretanto alguns participantes revelaram não utilizar a comunicação não-verbal com frequência: Eu olho pra ela mas fazer gesto assim não (P5); Eu olho só, mas não gesticulo (P3).

A comunicação não-verbal pode ser utilizada para complementar, substituir e até demonstrar sentimentos em portadores de transtorno mentais, devido ao embotamento afetivo, o distanciamento e a catatonia muitas ela é prejudicada(17). Após as intervenções, os participantes relataram uma melhoria do seu desempenho quanto à comunicação não verbal: Eu tentei olhar, mas não sei se elas entenderam (P5); Nessa eu tive dificuldade, porque tive vergonha, mas acho que eu desempenhei bem, desenvolvendo conforme o dia né (P3).

Assim observou-se que, apesar de timidez nas cenas, houve uma superação frente ao novo, a tentativa interação interpessoal, na troca de olhares e a busca pelo desenvolvimento dessa competência, possibilitando a assertividade e empatia na comunicação(18).

\section{Agrupamento de expressividade emocional}

O objetivo foi identificar se o sujeito percebia-se transmitindo alguma emoção durante a sua interação social com o interlocutor. Inicialmente o participante relatou: Acho que não consigo não (me expressar emocionalmente) (P1).

No entanto, a intervenção dos jogos teatrais se mostrou benéfica para esse mesmo participante que, no ambiente do jogo teatral destacou: Alguns jogos, algumas coisas sim. (...) quando tinha que fazer as duplas, os dois, eu e a P3, nós conseguimos fazer. Eu acho que nós conseguimos fazer, transmitir aquilo que a gente tava passando (P1).

A fala de P1 mostra que os jogos teatrais e a pareceria com os outros integrantes do grupo garantiram um ambiente de intimidade capaz de fazer P1 expressar a sua emoção, antes represada.

Em um grupo há fatores terapêuticos que permeiam a relação entre os participantes: a coesão grupal, o altruísmo, a aprendizagem vicária e a universalidade. A coesão grupal refere-se ao fato do membro se sentir pertencente e acolhido ao grupo. O altruísmo é a habilidade de mostrar-se sensível as dificuldades, aos problemas e aos limites de outro, sentindo o desejo de ajudá-lo, ou efetivamente fazendo algo para ajudá-lo no contexto grupal. Além desses, há ainda a aprendizagem vicária, que é reconhecer ter aprendido algo de valor para si, pela observação de outro membro do grupo; e a universalidade, que tange a percepção de não ser o único a ter problemas, ou reconhecer que outros membros do grupo têm problemas iguais ou maiores que os próprios ${ }^{(19)}$.

Esses fatores terapêuticos podem conduzir a mudanças nos comportamentos e nas competências sociais dos participantes de um grupo tal como ressalta Yalom, apontando que frequentemente membros mais antigos de grupos tem mais facilidade em sintonizarse com o processo, adquirem métodos de resolução de conflitos, são menos prováveis de julgar e mais capazes de experimentar e expressar empatia. Essas habilidades ajudam nas interações sociais futuras, e dão suporte para a inteligência emocional(19).

Somada aos fatores terapêuticos do grupo, os jogos teatrais são técnicas que contribuem para o desenvolvimento da expressividade emocional, como observou-se no relato de $\mathrm{P} 1$.

O jogo teatral propicia um ambiente de confiança nos parceiros do jogo, segurança emocional e ausência de tensão que criam condições propícias para a aprendizagem das competências sociais, já que a conduta lúdica oferece oportunidades para experimentar comportamentos que, em situações normais, jamais seriam tentados pelo medo do erro ou punição(19). Essa educação de forma lúdica estimula o desenvolvimento emocional e a sociabilidade(20).

Vemos um exemplo de desenvolvimento emocional e sociabilidade após a intervenção com os jogos teatrais na relato: Fiquei mais carinhoso com a minha mãe, é que mora eu e ela e o marido dela. Eu fiquei mais carinhoso com ela, mais atencioso. Ajudou bastante no convívio (P3).

\section{Agrupamento de solução de problemas}

Na pesquisa também foi identificada a percepção dos participantes a respeito da sua capacidade de solução de problemas, que é uma parte integrante do repertório de competências sociais ${ }^{(14)}$.

$\mathrm{Na}$ pergunta oito da entrevista inicial, os participantes relataram um problema do cotidiano, como, por exemplo, para realização de uma tarefa doméstica, e quais seriam os passos a serem dados na resolução desse problema: solicitar a ajuda de alguém na casa, pedir emprestado o utensílio a um vizinho, ir ao supermercado comprá-lo, etc. Abaixo estão os relatos dos participantes sobre as estratégias 
escolhidas para solucionar o problema: Às vezes eu peço pra minha cunhada ou eu pergunto pra outra pessoa. Eu sou difícil pedir as coisas. Eu não sou de ficar pedindo (P7). Eu ultimamente não ando resolvendo nada. A minha filha que faz o que tem que fazer (P1). Ajuda da minha mãe, toda vez que tem um problema em casa eu tenho que falar com ela (P4). Às vezes eu preciso de ajuda pra ir ao supermercado, não sei direito o que comprar (P9).

Foi marcante a necessidade de auxílio na resolução de problemas cotidianos. Familiares, vizinhos e amigos foram fortemente citados como contribuintes nessas resoluções. No entanto, após os jogos teatrais, alguns participantes relataram terem desenvolvido alguma autonomia e habilidade na solução de problemas, seja "no faz de conta" dos jogos ou em situações da vida real: Acho que sim, no último encontro que teve consegui olhar no rosto do outro, ver o que ele tá fazendo. Com outra pessoa é bom! (P1). Até que não, não precisei de ajuda não. Até fui mais eu mesmo! Ajudou bastante no convívio. Fiquei mais atencioso (P9). Noventa por cento precisei de ajuda. É porque você sabe que eu tenho um pouquinho de timidez, mas eu acho que eu consegui, dei o meu melhor. Melhorei, porque antes eu era de dar o dinheiro pra não sei quem, eu era assim bobão, agora melhorou (P7).

Esses dados parecem apontar que os jogos teatrais permitem a confrontação com os problemas e as tentativas de solucioná-los, desenvolvendo a competência social de solução de problemas. Dessa forma, o jogo teatral possibilitou de forma lúdica o "treino" de solução de problemas, que dificilmente seria possível fazer no cotidiano(21) pelas possíveis experiências desagradáveis ou medo de errar.

\section{Processo de Conscientização a partir dos Jogos Teatrais}

Alguns participantes pareceram ampliar a sua percepção a respeito de suas dificuldades com relação às competências sociais, após a intervenção com os jogos teatrais. Vê-se isso, por exemplo, quando antes dos jogos teatrais, o participante acreditar conseguir se expressar verbalmente de maneira clara, mas após o processo, reconhecer: De maneira clara, clara não, precisei de uma ajudinha (P6).

Uma demonstração de conscientização surge também quando há a percepção da complexidade de se expressar por gestos: Foi um pouco complicado né? Porque conversam gesticulando é mais difícil da pessoa entender né? Ou nem conversar, que nem daquela vez que o grupo que teve que a gente não podia conversar, só fazer gestos. Consegui, mas foi bem difícil (P2). Ou quanto a importância da articulação das palavras: Bem, articular palavras acho que foi assim, um pouco difícil (P8).

A princípio, a conscientização desses participantes a respeito das dificuldades com as medidas moleculares da competência social (agrupamento verbal, agrupamento não verbal e agrupamento pralinguístico, respectivamente) pode parecer um retrocesso. Contudo, esse pode ser um primeiro passo para os participantes avançarem para um aperfeiçoamento das competências sociais.

Portanto, os jogos de improvisação de Spolin possibilitaram um espaço de experiências sensoriais, corporais, emocionais e de inter-relação capazes de fazer com que os participantes adquirissem autoconsciência, um contato mais direto com o ambiente ${ }^{(16)}$, uma aproximação do próprio corpo e o do corpo do outro, evidenciando traços, modos de funcionamento, ativação de pensamentos, memória e imaginários como resultado desses oito encontros ${ }^{(22)}$.

\section{Conclusão}

Pelos resultados apresentados e o tempo de aplicação dos jogos ter sido relativamente curto, e, atrelado a isso, terem sido observados avanços nas competências sociais dos participantes, não se pode afirmar que essas aquisições sejam permanentes.

No entanto, não se pode negar influência positiva dos jogos nas competências sociais dos participantes do estudo e o potencial desses jogos teatrais como uma ferramenta terapêutica, que se constitui em linguagem de estrutura flexível e plástica, capaz de permitir a troca de experiências e facilitar a comunicação entre pessoas, sobretudo quando a linguagem comum é insuficiente para exteriorizar vivências singulares, principalmente em contextos coletivos, para facilitar a comunicação entre pessoas, visando o processo de reabilitação psicossocial.

Assim sendo, esse estudo demonstrou que os jogos teatrais podem ser incorporados nas atividades dos CAPS, por profissionais da equipe multiprofissional de saúde, que compreendam os fins e realizem supervisão periódica dos possíveis avanços, visando o desenvolvimento e treino das competências sociais e consequente reabilitação psicossocial de seus usuários.

Ressalta-se a necessidade de que novos estudos sejam realizados para ampliação dos resultados e discussão da temática. 


\section{Referências}

1. Yasui S. Rupturas e encontros -desafios da reforma psiquiátrica brasileira. Rio de Janeiro: FIOCRUZ; 2010.

2. Pitta AMF. Um balanço da reforma psiquiátrica brasileira: instituições, atores e políticas. Ciênc Saúde Coletiva. [Internet]; 2011 [Acesso 20 fev 2018]. Disponível em: http://www.scielo.br/scielo.php?script=sci_arttext\&pid=S $141381232011001300002 \&$ lng=en\&nrm=iso.

3. Mcfall RPA. A review and formulation of the concept of social skills. Behavioral Assess. [Internet].1982; 4(1):1-33. http://dx.doi.org/10.1007/BF01321377

4. Bandeira M, Ireno EM. Reinserção social de psicóticos: Avaliação global do grau de assertividade, em situações de fazer e receber crítica. Psicol: Reflex Crít. [Internet]; 2002 [Acesso 20 fev 2018]. Disponível em: http://www. scielo.br/scielo.php?script=sci_arttext $\&$ pid=S010279722002000300019\&lng=en\&nrm=iso.

5. Caballo VE. Manual de avaliação e treinamento das Habilidades Sociais. São Paulo: Editora Livraria Santos; 2006.

6. Del Prette ZAP, Del Prette A. Inventário de Habilidades Sociais - manual de aplicação, apuração e interpretação. $4^{a}$ ed. São Paulo: Casa do Psicólogo; 2009.

7. Del Prette ZAP, Del Prette A. Avaliação de habilidades sociais de crianças com um inventário multimídia: Indicadores sociométricos associados à frequência versus dificuldade. Psicol Estudo. 2002;7(1):61-73.

8. Löhr SS. Estimulando o desenvolvimento de habilidades sociais em idade escolar. In: Del Prette Z, Del Prette A. Habilidades sociais, desenvolvimento e aprendizagem. Campinas: Editora Alínea; 2003. p. 293-310.

9. Felissete RCM, Behlau M. Os jogos teatrais como recurso terapêutico complementar na doença de Parkinson: relato de uma experiência. São Paulo: Distúrbio Comum; 2010.

10. Furlan PM, Massimo R, Moncalvo M, Bernardi M, Rovelli G, Caratto L, et al. Terapias Expressiva: Teatro. J Nurs Health. 2012;2(Suppl 2):169-74. http://www.ufpel. edu.br/revistas/index.php/enfermagemesaude

11. Melo W, Ferreira AP. Clínica, pesquisa e ensino: Nise da Silveira e as mutações na psiquiatria brasileira. [Internet]. São Paulo (SP): Rev Latinoam Psicopatol Fund. [Internet]; 2013. [Acesso 21 fev 2018] Disponível em: http://www. scielo.br/scielo.php?script=sci_arttext\&pid=S141547142 013000400005\&lng=en\&nrm=iso.

12. Bardin L. Análise de conteúdo. Lisboa: Edições 70; 2011.

13. Spolin V. Os Jogos Teatrais: O fichário de Viola Spolin. $2^{\mathrm{a}}$ ed. São Paulo: Editora Perspectiva; 1975. 2012.

14. Bandeira M. Escala de Avaliação da Competência Social de Pacientes Psiquiátricos através de Desempenho de Papéis- EACS. Avaliação Psicol. 2002;2(1):159-71.
15. Organização Mundial da Saúde. Classificação Estatística Internacional de Doenças e Problemas Relacionados à Saúde. São Paulo: EDUSP; 1994.

16. Spolin V. Improvisação para o Teatro. São Paulo : Editora Perspectiva; 2006.

17. Almeida AFP. Comunicação, saúde mental e psicopatologia. Cad Comunicação Linguagem. 2009;12:1332.

18. Sequeira C. Comunicação terapêutica em saúde mental. Rev Portuguesa Enferm Saúde Mental. [Internet]. 2014 dez [Acesso 27 fev 2018] ;12:6-8. Disponível em: http://www.scielo.mec.pt/scielo.php?script=sci_ arttext\&pid=S1647-21602014000300001\&lng=pt.

19. Yalom ID. The theory and practice of group psychotherapy. 5th ed. New York: Basic Books; 2005.

20. Kamel ACA Filho. Jogos teatrais na escola: um estudo de caso acerca de interações e aprendizagens. [Dissertação]. Vitória (ES): PPGE/CE/UFES; 2009. p 124. 21. Carleto EA. O jogo no processo de evolução da aprendizagem. Olhares Trilhas. 2006; 7(7):89-98.

22. Liberman F, Sâmea M, Rosa SD. Laboratório de atividades expressivas na formação do terapeuta ocupacional. Cad Terap Ocupac UFSCar. 2011;1(19):81-92. 